\title{
Childhood diarrheal morbidity and sanitation predictors in a nomadic community
}

\author{
Bikes Destaw Bitew ${ }^{1}$, Wondwoson Woldu² and Zemichael Gizaw ${ }^{1 *}$
}

\begin{abstract}
Background: Diarrhea remains a leading killer of young children on the globe despite the availability of simple and effective solutions to prevent and control it. The disease is more prevalent among under - five children (U5C) in the developing world due to lack of sanitation. A child dies every $15 \mathrm{~s}$ from diarrheal disease caused largely by poor sanitation. Nearly $90 \%$ of diarrheal disease is attributed to inadequate sanitation. Even though, the health burden of diarrheal disease is widely recognized at global level, its prevalence and sanitation predictors among a nomadic population of Ethiopia are not researched. This study was therefore designed to assess the prevalence of childhood diarrheal disease and sanitation predictors among a nomadic people in Hadaleala district, Afar region, Northeast Ethiopia.

Methods: A community based cross-sectional study design was carried out to investigate diarrheal disease among U5C. A total of 704 households who had U5C were included in this study and the study subjects were recruited by a multistage cluster sampling technique. Data were collected using a structured questionnaire and an observational checklist. All the mothers of U5C found in the selected clusters were interviewed. Furthermore, the living environment was observed. Univariable binary logistic regression analysis was used to choose variables for the multivariable binary logistic regression analysis on the basis of $\mathrm{p}$ - value less than 0.2 . Finally, multivariable binary logistic regression analysis was used to identify variables associated with childhood diarrhea disease on the basis of adjusted odds ratio (AOR) with 95\% confidence interval (Cl) and $p<0.05$.

Results: The two weeks period prevalence of diarrheal disease among U5C in Hadaleala district was $26.1 \%$ (95\% Cl: 22.9 - 29.3\%). Childhood diarrheal disease was statistically associated with unprotected drinking water sources $[A O R=2.449,95 \% \mathrm{Cl}=(1.264,4.744)]$, inadequate drinking water service level $[A O R=1.535$, $95 \% \mathrm{Cl}=(1.004,2.346)]$, drinking water sources not protected from animal contact $[\mathrm{AOR}=4.403,95 \%$ $\mathrm{Cl}=(2.424,7.999)]$, un-availability of any type of latrine $[\mathrm{AOR}=2.278,95 \% \mathrm{Cl}=(1.045,4.965)]$, presence of human excreta in the compound $[\mathrm{AOR}=11.391,95 \% \mathrm{Cl}=(2.100,61.787)]$, not washing hand after visiting toilet $[A O R=16.511,95 \% \mathrm{Cl}=(3.304,82.509)]$, and live in one living room $[A O R=5.827,95 \% \mathrm{Cl}=(3.208,10.581)]$. (Continued on next page)
\end{abstract}

\footnotetext{
* Correspondence: zemichael12@gmail.com

${ }^{1}$ Department of Environmental and Occupational Health and Safety, Institute

of Public Health, College of Medicine and Health Sciences, University of

Gondar, Gondar, Ethiopia

Full list of author information is available at the end of the article
} 
(Continued from previous page)

Conclusion: Childhood diarrheal disease was the common public health problem in Hadaleala district. Compared with the national and regional prevalence of childhood diarrhea, higher prevalence of diarrhea among U5C was reported. Types of drinking water sources, households whose water sources are shared with livestock, volume of daily water collected, availability of latrine, presence of faeces in the compound, hand washing after visiting the toilet and number of rooms were the sanitation predictors associated with childhood diarrhea. Therefore, enabling the community with safe and continuous supply of water and proper disposal of wastes including excreta is necessary with particular emphasis to the rural nomadic communities.

Keywords: Childhood diarrheal disease, Under-five children, Environmental sanitation, Nomadic people, Multi variable binary logistic regression, Hadaleala district, Ethiopia

\section{Background}

Simple and effective solutions are available to prevent and control diarrheal disease.However, the disease remains a leading killer of young children on the globe, accounting for $9 \%$ of all deaths among U5C worldwide in 2015. This translates into over 1400 young children dying each day, or about 530,000 children a year. Most child deaths from diarrhea occur in South Asia and subSaharan Africa [1-3].

Diarrhea is more prevalent in the developing world due to the lack of safe drinking water, sanitation and hygiene, as well as poorer overall health and nutritional status. According to the latest available figures, an estimated 2.4 billion people lack improved sanitation facilities, and nearly 1 billion people do not have access to safe drinking water. These unsanitary environments allow diarrhea causing pathogens to spread more easily [4].

Diarrheal disease is a serious public health problem among U5C in developing countries. The rate of diarrheal infections in many developing countries is extremely high. Diarrheal pathogens are constantly being excreted into the environment and in massive quantities. As a direct consequence, in Ethiopia about 13\% of children under age of 5 years had diarrhea [5]. In the country, $24-30 \%$ of all infant deaths and $25 \%$ of deaths among children aged between 1 and 4 years were due to diarrhea [6]. Similarly, diarrheal disease was also the major cause of $12.7 \%$ under-five mortality in the Afar region, where the area of the current study is located [5].

Studies all over the world illustrated that childhood diarrhea is the result of many factors. However, the overwhelming causes are associated with poor sanitation. Diarrheal disease due to lack of sanitation is the greatest cause of morbidity and mortality among U5C in the world, especially in poor countries [7-10]. A child dies every $15 \mathrm{~s}$ from diarrheal disease caused largely by poor sanitation [11]. Nearly $90 \%$ of diarrheal disease is attributed to inadequate sanitation $[8,12]$.

Although, the health burden of diarrheal disease is widely recognized at global level, its prevalence and sanitation predictors among the nomadic populations of
Ethiopia are not researched. This study was therefore designed to assess the prevalence of childhood diarrheal disease and sanitation predictors among nomadic people in Hadaleala district, Afar region, Northeast Ethiopia.

\section{Methods}

\section{Study design and description of study settings}

A community based cross-sectional study was conducted in Hadaleala district, Afar region, Northeast Etiopia from April 28 to May 17, 2015. Hadaleala district is one of the districts found in Hariresu zone, the Afar National Regional State. It is located at $341 \mathrm{~km}$ to the Southwest direction from the regional capital city Semera and $268 \mathrm{~km}$ away to the North of Addis Ababa, the capital of Ethiopia. In the district, an estimated 7516 households were found with an average household size of 5.7 persons per house and with an U5C population of $10.1 \%$. The population lives in a very scattered manner where the average population density is 14 persons $/ \mathrm{km}^{2}$, which makes the establishment of basic sanitation facilities difficult. The community who lives in all kebeles (the lowest administrative units) of the district is mobile pastoralist. The community suffers from a shortage of water, hygiene and sanitation facilities. During 2015, safe water and sanitation coverage of the district was 35\% and $12 \%$, respectively [13].

\section{Sample size determination}

The sample size was determined using single population proportion formula by considering these assumptions: $p=31 \%$ (the two weeks period prevalence of diarrhea among U5C in Arbaminch district) [14], 95\% confidence interval, $5 \%$ margin of error (d),

$$
n=\frac{\left(z_{\alpha / 2}\right)^{2} p(1-p)}{d^{2}}=\frac{(1.96)^{2} 0.31(1-0.31)}{0.05^{2}}=328
$$

Considering the design effect of 2 and 5\% non response rate, the final sample size was 689 mothers-child pair. 


\section{Sampling procedures}

For the reason that the study participants are nomadic and scattered, multistage cluster sampling technique was used to select study participants. The clusters were villages with defined geographical boundaries. From a total of 11 kebeles, 6 were randomly selected by a lottery method. The selected 6 kebeles were clustered into 39 villages and from these villages, 17 were selected by systematic random sampling technique. Finally, all (704) households who had U5C were included in the study. For households having more than one child, the younger one was taken as index child and recruited in the study.

\section{Measurement of study variables}

Childhood diarrheal disease, which was the outcome variable of this study was defined as having three or more loose or watery stools within $24 \mathrm{~h}$ period $[15,16]$. The prevalence of diarrhea within the two weeks period prior to data collection was calculated as the total number of diarrhea cases divided by the total number of $\mathrm{U} 5 \mathrm{C}$ in the study area. The predictor variables were defined based on the minimum or basic indicators for access to basic sanitation set by the World Health Organization (WHO) and United Nations Children's Fund (UNICEF) [17].

\section{Data collection tools and procedures}

A structured questionnaire and an observational checklist were used to collect data. The tools were prepared in English language and translated to the local language and back translated to English to maintain the consistency of the questions. Prior to the actual data collection period, the tools were pre-tested out of the study area. To increase quality of data, eight diploma nurses and two Environmental Health Officers who were fluent in speaking both Amharic and Afarigna language and working in the district were involved in the data collection process. After pretest and training of data collectors, the collectors had visited all households found in the selected clusters. When collectors got U5C during the visit, they asked the mothers and observed the living environment. The younger children were included in the study when there were more than one $\mathrm{U} 5 \mathrm{C}$ in the household. Finally, the collected data were checked and corrected by the data collectors immediately after finalizing the questionnaire. Supervisors had also checked the completeness of all the daily filled questionnaires and $5 \%$ of the collected questionnaires were repeated.

\section{Data management and statistical analysis}

Data were entered using EPI-INFO version 3.5.3 statistical package and exported into SPSS version 20.0 for further analysis. For most variables, data were presented by frequencies and percentages. Univariable binary logistic regression analysis was used to choose variables for the multivariable binary logistic regression analysis and variables which had a $\mathrm{p}$ - value less than 0.2 by the univariable analysis were then analyzed by multivariable binary logistic regression for controlling the possible effect of confounders and finally, variables which had association were identified on the basis of AOR with $95 \%$ CI and a $p<0.05$.

\section{Results}

\section{Sanitation condition in the nomadic community}

Drinking water sources and water handling at home, excreta management, solid waste disposal, and housing conditions were assessed by the current study. The majority, $453(64.3 \%)$ of households had collected water from unprotected water sources. Three hundred seventy-three $(53.0 \%)$ households had collected water below $15 \mathrm{~L} / \mathrm{C} / \mathrm{d}$. More than two - third, 488 (69.3\%) of the households stored drinking water in wide mouthed containers and almost all of the households did not properly cover the storage containers at the time of the survey. Six hundred eighty-four (97.2\%) of the households drew water from the storage container by pouring. A small proportion (4.8\%) of the households practiced home based water treatment. More than three fold, 563 $(80.0 \%)$ of the households didn't have latrines. Residents of six hundred thirty-seven (90.5\%) households did not wash their hands after visiting toilet. Moreover, the great majority of the households, $621(88.2 \%)$ had practiced indiscriminate waste disposal. Five hundred ninety-four (84.4\%) of the households lived in a house with earthen floor and most, 398 (56.5\%) of the dwellings had only one room (Table 1).

\section{Prevalence of childhood diarrheal disease}

Mothers were asked about the history of their childhood diarrhea in the past two weeks prior to the data collection period. Accordingly, mothers reported that a total of 184 children had diarrheal disease. Therefore, the two weeks period prevalence of diarrhea among U5C was found to be $26.1 \%$ (95\% CI: $22.9-29.3 \%)$. In addition, the occurrence of diarrhea at the time of the survey was also assessed and the report indicated that 81 children had diarrhea at the time of data collection. The point prevalence of diarrhea was therefore $11.5 \%$ (95\% CI: 9.1, 13.8\%).

\section{Factors associated with childhood diarrheal disease}

Types of drinking water sources, condition of water sources, household storage of water, method of withdrawing of water from the container, home based water treatment, covering water storage container, volume of water collected, availability of latrine, presence of faeces in the compound, hand washing after visiting toilet, floor type, number of rooms, and refuse management 
Table 1 Sanitation condition of households in the nomadic population ( $n=704$ ) of Hadaleala district, Afar region, Northeast Ethiopia

\begin{tabular}{lll}
\hline Variables & Frequency & Percent \\
\hline Drinking water source & & \\
Protected & 251 & 35.7 \\
Unprotected & 453 & 64.3 \\
Drinking water source shared with livestock & \\
$\quad$ Yes & 374 & 53.1 \\
No & 330 & 46.9 \\
Average per capita water consumption & & \\
$\quad \leq 15$ I & 373 & 53.0 \\
$\quad>15$ I & 331 & 47.0 \\
Water storage container & & \\
Wide mouthed containers & 488 & 69.3 \\
Narrow mouthed containers & 216 & 30.7
\end{tabular}

Water storage containers were properly covered the time of the survey

$\begin{array}{lll}\text { Yes } & 26 & 3.7 \\ \text { No } & 678 & 96.3\end{array}$

How to withdrawal water from the storage

$\begin{array}{lll}\text { Pouring } & 684 & 97.2 \\ \text { Dipping } & 20 & 2.8 \\ \text { Home based water treatment } & & \\ \text { Yes } & 34 & 4.8 \\ \text { No } & 670 & 95.2\end{array}$

Common methods of home based treatment

\begin{tabular}{lll} 
Chlorination & 32 & 94.12 \\
Sedimentation & 2 & 5.88 \\
Availability of any type of latrine & & \\
Yes & 141 & 20.0 \\
No & 563 & 80.0 \\
Reason for not having latrine & & \\
Temporary settlement & 323 & 57.37 \\
Knowledge gap & 155 & 27.53 \\
Cultural issues & 85 & 15.10 \\
Hand washing after visiting the toilet & & \\
Yes & 67 & 9.5 \\
No & 637 & 90.5 \\
Refuse disposal method & & \\
Controlled disposal & 83 & 11.8 \\
Open field & 621 & 88.2 \\
Types of floor & & \\
Earth floor & & \\
Plastered concrete floor & 594 & 15.6 \\
Number of rooms & 110 & 56.5 \\
One & & \\
Two & 398 & \\
\hline
\end{tabular}


Table 2 Sanitation predictors of childhood diarrhea among U5C ( $n=704)$ in Hadaleala district, Afar region, Northeast Ethiopia, May

\begin{tabular}{|c|c|c|c|c|}
\hline \multirow[t]{2}{*}{ Environmental variables } & \multicolumn{2}{|c|}{ Childhood diarrhea } & \multirow[t]{2}{*}{ COR with $95 \% \mathrm{Cl}$} & \multirow[t]{2}{*}{ AOR with 95\% Cl } \\
\hline & Yes & No & & \\
\hline \multicolumn{5}{|l|}{ Drinking water source } \\
\hline Protected & 16 & 235 & 1 & \\
\hline Unprotected & 168 & 285 & $8.658(5.040,14.873)$ & $2.449(1.264,4.744)^{\mathrm{a}}$ \\
\hline \multicolumn{5}{|l|}{ Volume of water collected } \\
\hline$\leq 15 \mathrm{~L} / \mathrm{C} / \mathrm{d}$ & 127 & 246 & $2.482(1.737,3.546)$ & $1.535(1.004,2.346)^{\mathrm{a}}$ \\
\hline$>15 \mathrm{~L} / \mathrm{C} / \mathrm{d}$ & 57 & 274 & 1 & \\
\hline \multicolumn{5}{|c|}{ Water is shared with livestock at the source } \\
\hline Yes & 163 & 211 & $11.367(6.985,18.498)$ & $4.403(2.424,7.999)^{a}$ \\
\hline No & 21 & 309 & 1 & \\
\hline \multicolumn{5}{|c|}{ The water storage container is covered at the time of the survey } \\
\hline Yes & 2 & 24 & 1 & \\
\hline No & 182 & 496 & $4.403(1.030,18.818)$ & $15.681(0.191,1287.490)$ \\
\hline \multicolumn{5}{|c|}{ How to withdraw water from the storage } \\
\hline Pouring & 182 & 502 & 1 & \\
\hline Dipping & 2 & 18 & $0.306(0.070,1.334)$ & 16.464(0.191, 1421.947) \\
\hline \multicolumn{5}{|c|}{ Availability of any type of latrine } \\
\hline Yes & 21 & 120 & 1 & \\
\hline No & 163 & 400 & $2.329(1.415,3.832)$ & $2.278(1.045,4.965)^{\mathrm{a}}$ \\
\hline \multicolumn{5}{|c|}{ Faeces observed in the compound } \\
\hline Yes & 179 & 457 & $4.935(1.953,12.470)$ & $11.391(2.100,61.787)^{\mathrm{a}}$ \\
\hline No & 5 & 63 & 1 & \\
\hline \multicolumn{5}{|c|}{ Hand washing after visiting the toilet } \\
\hline Yes & 173 & 464 & 1 & \\
\hline No & 11 & 56 & $0.527(0.270,1.029)$ & $16.511(3.304,82.509)^{\mathrm{a}}$ \\
\hline \multicolumn{5}{|l|}{ Number of rooms } \\
\hline Only one room & 167 & 231 & $12.290(7.248,20.840)$ & $5.827(3.208,10.581)^{\mathrm{a}}$ \\
\hline Two rooms & 17 & 289 & 1 & \\
\hline \multicolumn{5}{|l|}{ Floor type } \\
\hline Earth floor & 168 & 426 & $2.317(1.324,4.053)$ & $2.039(0.938,4.434)$ \\
\hline Cemented floor & 16 & 94 & 1 & \\
\hline
\end{tabular}

The result of Hosmer and lemshow test was $>0.05$

${ }^{\text {a}}$ Statistically significant variables

as compared with their counterparts $[\mathrm{AOR}=16.511$, 95\% CI $=(3.304,82.509)]$.

Diarrheal disease was also associated with housing condition, particularly the number of rooms was associated with childhood diarrhea. Children who lived in houses with only one room had more chance to develop diarrhea than children who lived in houses with two rooms. As depicted by this study, the likelihood of having diarrhea was about 5.8 times more likely to be higher among children who lived in houses with only one room compared with children who lived in houses with two rooms $[\mathrm{AOR}=5.827$, 95\% CI $=(3.208,10.581)]$.

\section{Discussion}

This community based cross sectional study found that the prevalence of diarrheal disease among the U5C of the nomadic people of Hadaleala district was $26.1 \%$ (95\% CI: $22.9,29.3 \%)$, which is higher than the national prevalence, $13 \%$ [18]. The prevalence of childhood diarrhea reported by this study was higher than the report of other similar studies in Ethiopia, like in eastern Ethiopia (22.5\%) [19], Bahir Dar city (21.6\%) [20], Mecha district (18\%) [21] and Sebeta (9.9\%) [22]. On the other, it was lower than the result of studies conducted in Nekemte (28.9\%) [23], and Arba Minch district (30.5\%) [24]. The variation of results among the studies might be due to 
the difference in the socio-demographic, environmental and behavioral characteristics of households or mothers, and differences in climatic condition.

The water sources in which the community collected drinking water had a significant effect on the development of childhood diarrheal disease. Children whose families accessed drinking water from unprotected sources had a greater chance to develop diarrhea. This can be explained that unprotected water sources are prone to contamination with human and animal wastes containing a number of diseases causing pathogenic microorganisms which have been associated with increased risks of a range of diarrheal diseases in children. The result of this study was also consistent with the findings of other similar studies [19, 25-30].

The childhood diarrheal disease was associated with the quantity of water collected for daily domestic uses. Those households who had had inadequate service level (below $15 \mathrm{~L} / \mathrm{C} / \mathrm{d}$ ) were highly affected by childhood diarrhea.The finding of this study was also in line with the findings of other studies conducted all over the world [31-33]. This might be due to the fact that access to adequate service level has an association with the frequency of hygiene behaviors of the households. It is very difficult to keep the personal hygiene and cleanliness of utensils if there is a shortage of water.

This study had explained that childhood diarrhea was associated with exposure of drinking water sources for livestock. The childhood diarrheal disease was highly prevalent among households whose water source were shared with livestock. Other studies had also reported similar findings with the current study [27, 29]. This could be justified that drinking water sources which are not free from animal contact may contain diseases causing pathogenic microorganisms which come from animal excreta and urine.

Availability of any type of latrine and open defecation were associated with childhood diarrhea. As revealed by this and other similar studies, children lived in areas characterized by open defecation were more affected by diarrheal disease [19-23, 25]. This might be due to the fact that a human excreta contains millions of diseases causing pathogenic microorganisms. Indiscriminately managed human excreta pollutes the living environment and the children may get contaminated by pathogenic microorganisms during crawling, walking and playing. Furthermore, poorly managed human excreta may pollute drinking water sources and different food items and it creates favorable conditions for vector breeding which cause a wide spread of diarrhea.

Households' hand washing practice after visiting toilet was statistically associated with childhood diarrhea. The importance of hand washing after visiting toilet to minimize the load of microorganisms has been also documented. This could be explained that human hands might be contaminated with microorganisms during defecation and contaminated fingers are the main routes for feco-oral disease transmissions [19, 24, 34-36].

This research showed that childhood diarrheal disease was associated with number of habitable rooms. Childhood diarrhea was more prevalent among households who had only one living room compared with households having two or more living rooms. Similar findings were also reported by earlier studies in developing countries $[37,38]$. This might be due to the fact that crowded living rooms may create a chance of close contact among children, which creates a favorable condition for transmission of diseases causing pathogenic microorganisms.

Lastly, even if childhood diarrhea was properly defined using the WHO diarrhea assessment tool, its occurrence was determined based on the report of mothers. It was not confirmed by physicians. Due to this phenomenon, the current study might be affected by social desirability bias. However, strong efforts were made to minimize social desirability bias. Female enumerators who were part of the community were recruited for the purpose of creating strong relationships and links with mothers.

\section{Conclusions}

Childhood diarrheal disease was the common public health problem among nomadic communities in Hadaleala district. Compared with the national and regional prevalence of childhood diarrhea, higher prevalence of diarrhea among U5C was reported in the community. This study had also identified that types of drinking water sources, households whose water sources are shared with livestock, volume of daily water collected, availability of latrine, presence of faeces in the compound, hand washing after visiting toilet and number of rooms were sanitation predictors associated with childhood diarrhea in Hadaleala district, Afar region. Therefore, enabling the community with safe and continuous supply of water and proper disposal of wastes including excreta is necessary with particular emphasis to the rural nomadic communities.

\section{Abbreviations \\ AOR: Adjusted Odds Ratio; Cl: Confidence Interval; COR: Crude Odds Ratio; $\mathrm{Km}$ : Kilometer; $\mathrm{Km}^{2}$ : Kilometer square; L/C/d: Liter per capita per day; SPSS: Statistical Package for Social Sciences; U5C: Under - five children; UNICEF: United Nations International Children's Fund; WHO: World Health Organization}

\section{Acknowledgments}

The authors are pleased to acknowledge data collectors, field supervisors and study participants, Hadaleala district health office, Afar regional health bureau for their unreserved contribution for the success of this study. The authors would like to extend their gratitude to Hadaleala district administrators for their facilitation.

\section{Funding}

This study had no any special fund. However, University of Gondar had covered questionnaire duplication and data collection fee. 


\section{Availability of data and materials}

Data will be made available upon requesting the primary author.

\section{Authors' contributions}

All the authors actively participated during conception of the research issue, development of a research proposal, data collection, analysis and interpretation, and writing various parts of the research report. This final manuscript is prepared by Mr. Zemichael Gizaw. All the authors read and approved the final manuscript.
\end{abstract}

\section{Ethics approval and consent to participate}

Ethical clearance was obtained from institutional review board of the University of Gondar and official letter was submitted to the district administrators. Formal letter was also obtained from the Afar regional health bureau and Hadaleala district health office. The questionnaire was anonymously prepared and proved not to affect the moral and personality of study subjects. There were no risks due to participation in this research project and the collected data were used only for this research purpose. Verbal informed consent was obtained from mothers and mothers were informed about the objective of the study. Confidentiality was granted for the information collected from each household and privacy during the interview was ensured. During the data collection time, oral rehaydration solution and Zink tablet with clear instructions were given to children who had diarrhea and advice was given to mothers to take their children to a health institution for further management.

\section{Consent for publication}

This manuscript does not contain any individual person's data.

\section{Competing interests}

The authors declare that they have no competing interests.

\section{Publisher's Note}

Springer Nature remains neutral with regard to jurisdictional claims in published maps and institutional affiliations.

\section{Author details}

'Department of Environmental and Occupational Health and Safety, Institute of Public Health, College of Medicine and Health Sciences, University of Gondar, Gondar, Ethiopia. ${ }^{2}$ Hadaleala District Health Office, Hadaleala District, Hadaleala town, Afar Regional State, Ethiopia.

\section{Received: 18 May 2017 Accepted: 2 October 2017}

\section{Published online: 06 October 2017}

\section{References}

1. UNICEF. Diarrhea remains a leading killer of young children, despite the availability of a simple treatment solution, 2015. Available at http://data. unicef.org/child-health/diarrhoeal-disease.html. Accessed 15 Aug 2016.

2. U.S. Department of Health and Human Services. Diarrhea: Common IIIness, Global Killer. Available at https://www.cdc.gov/healthywater/pdf/global/../ globaldiarrhea508c.pdf. Accessed on 21 Aug 2016.

3. Liu L, Johnson HL, Cousens S, et al. Child health epidemiology reference group of WHO and UNICEF. Global, regional, and national causes of child mortality: an updated systematic analysis for 2010 with time trends since 2000. Lancet. 2012;379(9832):2151-61.

4. WHO/UNICEF Joint Monitoring Programme and is the final report on access to drinking water and sanitation ahead of the MDG's, 2015. Available at http://www.who.int/water_sanitation_health/monitoring/jmp-2015-keyfacts/en/. Accessed 23 Aug 2016.

5. Central Statistical Agency (CSA). Ethiopia Demographic and Health Survey 2011, Addis Ababa, Ethiopia. Availlable at www.unicef.org/ethiopia/ET_ 2011_EDHS.pdf. Accessed 22 Aug 2016.

6. Ahmed Ehsanur Rahman, Md Moinuddin, Mitike Molla, et.al. Childhood diarrheal deaths in seven low- and middle-income countries, 2014. Available at http:// www.who.int/bulletin/volumes/92/9/13-134809/en/. Accessed 20 Aug 2016.

7. Fewtrell L, Kaufmann RB, Kay D, Enanoria W, Haller L, Colford JM Jr. Water, sanitation, and hygiene interventions to reduce diarrhea in less developed countries: a systematic review and meta-analysis. Lancet Infect Dis. 2005;5:42-52.

8. Ahs JW, Wenjing T, Lofgren J, Forsberg BC. Diarrhoeal diseases in low- and middle-income countries. Open Infect Dis J. 2010;4(123):113-24.
9. Baker KK, O'Reilly CE, Levine MM, et al. Sanitation and hygiene-specific risk factors for moderate-toSevere diarrhea in young children in the global enteric multicenter study, 2007-2011: case-control study. PLoS Med. 2016; 13(5):e1002010. doi: 10.1371/journal.pmed.1002010.

10. Cairncross $S$, Hunt $C$, Boisson $S$, et al. Water, sanitation and hygiene for the prevention of diarrhoea. Int J Epidemiol. 2010;39:1193-205. doi: 10.1093/ije/dyq035.

11. Barreto ML, Genser B, Strina A, et al. Effect of city-wide sanitation programme on reduction in rate of childhood diarrhoea in northeast Brazil: assessment by two cohort studies. Lancet. 2007;370:1622-8.

12. UNICEF. Progress for children: A report card on water and sanitation. Number 5, September 2006. Available at http://www.unicef.org/ publications/files/Progress_for_Children_No._5___English.pdf. Accessed 17 July 2017.

13. Alisadik DH, et al. Ethiopia: Hadaleala district Finance and economic development office annual report 2014. Hadaleala: Office of Finance and Economic Development Afar Region, Ethiopia; 2014. https://ibrary.mcmaster.ca/govpubs/cite.

14. Mohammed S, Tilahun M, Tamiru D. Morbidity and associated factors of diarrheal diseases among under five children in Arba-Minch district, southern Ethiopia. Sci J Public Health. 2012;1(2):102-6.

15. UNICEF/WHO. Diarrhoea: Why children are still dying and what can be done. The United Nations Children's Fund/World Health Organization, Geneva, 2009. Availlable at www.unicef.org/.../Final_Diarrhoea_Report_ October_2009_final.pdf. Accessed 18 May 2016.

16. Black RE, Morris SS, Bryce J. Where and why are 10 million children dying every year? Lancet. 2003;361:2226-34.

17. World Health Organization and United Nations Children's Fund Joint Monitoring Programme for Water Supply and Sanitation (JMP). Progress on drinking water and sanitation: special focus on sanitation. New York and Geneva: UNICEF and WHO; 2008. Available at www.wssinfo.org/fileadmin/ user_upload/resources/1251794333-JMP_08_en.pdf. Accessed 20 July 2016

18. Central Statistical Agency (CSA). Ethiopia Mini Demographic and Health Survey 2014, Addis Ababa, Ethiopia. Available at: www.unicef.org/ethiopia/ Mini_DHS_2014_Final_Report.pdf. Accessed 17 Aug 2016.

19. Mengistie $B$, Berhane $Y$, Worku A. Prevalence of diarrhea and associated risk factors among children under-five years of age in eastern Ethiopia: a crosssectional study. Open J Prev Med. 2013;3(7):446-53.

20. Gedefaw M, Takele M, Aychiluhem M, Tarekegn M. Current status and predictors of Diarrhoeal diseases among under-five children in a rapidly growing urban setting: the case of City Administration of Bahir Dar, Northwest Ethiopia. Open J Epidemiol. 2015;5:89-97.

21. Dessalegn M, Kumie A, Tefera W. Predictors of under-five childhood diarrhea: Mecha District, west Gojam, Ethiopia. Ethiop J Health Dev. 2011;25(3):192-200.

22. Mohammed Al, Zungu L. Environmental health factors associated with diarrheal diseases among under-five children in the Sebeta town of Ethiopia. South Afr J Infect Dis. 2016;1(1):1-8. doi: 10.1080/23120053.2016.1156876.

23. Regassa G, Birke W, Belachew T. Environmental determinants of diarrhea among under-five children in Nekemte town, Western Ethiopia. Ethiop J Health Sci. 2008;18:2.

24. Mohammed S, Tamiru D. The Burden of Diarrheal Diseases among Children under Five Years of Age in Arba Minch District, Southern Ethiopia, and Associated Risk Factors: A Cross-Sectional Study. International Scholarly Research Notices. 2014:6. Article ID 654901 https://doi.org/10.1155/2014/ 654901. Accessed 16 Aug 2016.

25. Boadi KO, Kuitunen M. Childhood diarrheal morbidity in the Accra Metropolitan Area, Ghana: Socio-economic, environmental and behavioral risk determinants. J Health Popul Dev Ctries. 2005; http://www.jhpdc.unc.edu/. Accessed 20 Aug 2016.

26. Kamal M, Hasan M, Davey R. Determinants of childhood morbidity in Bangladesh: evidence from the demographic and health survey 2011. BMJ Open. 2015;5(10):e007538.

27. Burkholder J, Libra B, Weyer P, Heathcote S, Kolpin D, Thorne PS, Wichman $\mathrm{M}$. Impacts of waste from concentrated animal feeding operations on water quality. Environ Health Perspect. 2007;115(2):308-12.

28. Shaheed A, Orgill J, Montgomery MA, Jeuland MA, Brown J. Why "improved" water sources are not always safe? Bull World Health Organ. 2014;92:283-9. doi: 10.2471/BLT.13.119594.

29. Shields KF, Bain RE, Cronk R, Wright JA, Bartram J. Association of Supply Type with fecal contamination of source water and household stored drinking water in developing countries: a Bivariate meta-analysis. Environ Health Perspect. 2015;123(12):1222-31. 
30. Plate DK, Strassmann BI, Wilson ML. Water sources are associated with childhood diarrhea prevalence in rural east-central Mali. Trop Med Int Health. 2004;9(3):416-25.

31. Zwane AP, Kremer M. What works in fighting diarrheal diseases in developing countries? A critical review. World Bank Res Obs. 2007;22(1):1-24.

32. World Health Organization (WHO). Domestic Water Quantity, Service, Level and Health. Available at www.who.int/water_sanitation_health/diseases/ WSH0302.pdf. Accessed 20 Aug 2016.

33. Pickering AJ, Davis J. Freshwater availability and water fetching distance affect child health in sub-Saharan Africa. Environ Sci Technol. 2012;46:2391-7.

34. Heller L, Colosimo A, Antunes C. Environmental sanitation conditions and health impact: a case-control study. Rev Soc Bras Med Trop. 2003;36(1):41-50.

35. Curtis V, Cairncross S. Effect of washing hands with soap on diarrhea risk in the community: a systematic review. Lancet Infect Dis. 2003;3(5):275-81.

36. Gebru T, Taha M, Kassahun W. Risk factors of diarrheal disease in under-five children among health extension model and non-model families in Sheko district rural community, Southwest Ethiopia: comparative cross-sectional study. BMC Public Health. 2014;14:395.

37. Siziya S, Muula AS, Rudatsikira E. Correlates of diarrhoea among children below the age of 5 years in Sudan. Afr Health Sci. 2013;13(2):376-83.

38. Mohammed S, Tamiru D. The occurrence of childhood diarrhea and its home management among mothers of under-five years children in Arba Minch Zuria, southern Ethiopia. Sci J Public Health. 2013;1(3):135-40. doi: 10.11648/j.sjph.20130103.15.

\section{Submit your next manuscript to BioMed Central} and we will help you at every step:

- We accept pre-submission inquiries

- Our selector tool helps you to find the most relevant journal

- We provide round the clock customer support

- Convenient online submission

- Thorough peer review

- Inclusion in PubMed and all major indexing services

- Maximum visibility for your research

Submit your manuscript at www.biomedcentral.com/submit 